\title{
Nurses' and doctors' expectations towards neuroleptic response in dementia
}

\author{
Simon Thacker
}

\begin{abstract}
A survoy of a group of doctors and nurses specialling in the care of the elderty demonstrated a wide range of opinions on the usetulness of major tranquillisers for controlling behovioural disturbance in dementia. However, there was 'broad agreement' among medical and nursing respondents that these drugs were unilikely to be helptul in controlling non-violent reatstiveness and sexual incppropriateness. The nurses incilcated less 'taith' in nouroleptic thercapy than their medical counterpats. The importance of auditing the use of major tranquillisers in dementia is emphasised.
\end{abstract}

The use of major tranquillisers to control behavioural problems in dementia has been a source of controversy for three decades. Although few clinicians would doubt the usefulness of these drugs for the urgent calming of severely disturbed patients with dementia, their long-term, regular use has been criticised on several grounds:

(a) The paucity of research evidence demonstrating their efficacy in controlling specific behavioural features of dementia. A metaanalysis of randomised, controlled clinical trials of neuroleptics in dementia suggested an effect size in reducing 'agitation' of only $18 \%$ for the active agents (Schneider, 1990).

(b) The proven risk of producing unwanted effects both immediate and 'tardive' (Mulsant \& Gershon, 1993).

(c) The high prevalence of neuroleptic prescribing in long-stay nursing establishments for the elderly has been viewed as excessive and poorly monitored (Nygaard et al, 1994; Avorn \& Gurwitz, 1995).

In the USA, these concerns have led to federal legislation enforcing guidelines for the prescription of major tranquillisers in Medicaid funded nursing homes. No such measures are afoot in the UK, where good practice relies on the judgement of doctors and nurses working within long-stay care facilities. This study aims to assess and compare between professional groups the expectations towards neuroleptic response in the behavioural problems of dementia sufferers.

\section{The study}

A questionnaire was sent to qualified nurses on all long-stay, National Health Service (NHS) psychogeriatric units and private nursing homes for the elderly mentally ill with at least some NHSfunded beds, within the Nottingham Health District. Medical respondents were sought from current psychogerlatric and gerlatric staff in the same area, who were consultants, assoclate specialists, staff grades, clinical assistants or specialist registrars. The questionnaire comprised the following vignette:

"An 80-year-old man with an established diagnosis of severe Alzheimer dementla, but no previous psychiatric history, has untll the last three months been settled in a nursing home. He has gradually developed behavioural disturbance that has proved resistant to simple non-drug measures. Medical examination has revealed no evidence of depression or physical illness."

Respondents were asked to assess the likelihood of whether the regular administration of major tranquillisers would help to reduce one of a list of behavioural problems (predictable physical aggression, unpredictable physical aggression, purposeless overactivity, wandering without overactivity, non-violent resistiveness, persistent shouting for no apparent reason, non-violent sexual inappropriateness, paranoid thinking such as repeated allegations of theft and shouting out at hallucinations) without unacceptable sideeffects and to register their judgements on a 6point Likert scale ranging from very unlikely to be helpful' to 'very likely to be helpful'. For each respondent these scores were summed to dertve a total 'faith in neuroleptics' score; written comments were encouraged. Basic professional details were requested, including an estimate of the respondent's duration of experience working with the elderly.

The Mann-Whitney test was used for the comparison of numerical data and the binomial test on proportions was used for dichotomised data. 


\section{Findings}

\section{Characteristics of respondents}

Seventy questionnaires were sent to nursing staff in four NHS wards and two large nursing homes. Thirty-one replies were recelved, a response rate of $42 \%$. Twenty-seven of these respondents were registered or enrolled mental nurses, including seven who were qualified in both general and psychiatric nursing; four were qualified solely in general nursing. Duration of experience in health care of the elderly ranged from one to 34 years (median 10). Thirty-eight questionnaires were sent to medical staff of whom 30 replied (response rate $79 \%$ ). Thirteen psychogeriatricians (4 consultants, one staff grade, 2 clinical assistants and 6 senior registrars) and 17 geriatricians (11 consultants, one associate specialist, one staff grade and 4 specialist registrars) responded. Duration of experience in health care of the elderly ranged from 6 months to 31 years (median 7 years).

Median values of the ratings of the likelihood of a helpful neuroleptic response for each behavioural problem are presented, broken down by professional group of the respondent, in Table 1. Despite the use of an even-numbered scale to deter a response bias to the centre, most median ratings are at the middle of the scale (2 or 4$)$. The highest median ratings (5) were given by the psychiatrists and gerlatricians respectively for hallucinations and by the geriatricians for paranoid thinking. The lowest median ratings (2) were provided by the nurses and gerlatricians respectively for resistiveness and by the nurses for inappropriate sexual behaviour. The ranges of responses were broad, particularly for the categories of predictable aggression, sporadic aggression, purposeless overactivity, shouting and wandering.

Table 1. Median ratings (range in brackets) of likellhood of neuroleptic helpful response for each indication

\begin{tabular}{|c|c|c|c|}
\hline Behoriour & Poychiatrists & Geriaticicians & Nurses \\
\hline $\begin{array}{l}\text { Predictable } \\
\text { aggression }\end{array}$ & $4(2-5)$ & $4(1-6)$ & $4(1-5)$ \\
\hline $\begin{array}{l}\text { Unpredictable } \\
\text { aggression }\end{array}$ & $4(2-6)$ & $3(3-6)$ & $4(1-6)$ \\
\hline $\begin{array}{l}\text { Purposeless } \\
\text { overactivity }\end{array}$ & $4(1-5)$ & $4(2-6)$ & $3(1-6)$ \\
\hline $\begin{array}{l}\text { Wandering } \\
\text { Non-violent } \\
\text { resistiveness }\end{array}$ & $\begin{array}{l}3(1-6) \\
3(2-5)\end{array}$ & $\begin{array}{l}3(1-6) \\
2(1-4)\end{array}$ & $\begin{array}{l}3(1-6) \\
2(1-5)\end{array}$ \\
\hline $\begin{array}{l}\text { Shouting } \\
\text { Non-violent sexual } \\
\text { inappropriateness }\end{array}$ & $\begin{array}{l}4(2-5) \\
3(1-4)\end{array}$ & $\begin{array}{l}4(1-6) \\
3(1-4)\end{array}$ & $\begin{array}{l}3(1-5) \\
2(1-4)\end{array}$ \\
\hline $\begin{array}{l}\text { Paranold thinking } \\
\text { Hallucinations }\end{array}$ & $\begin{array}{l}4(2-6) \\
5(4-6)\end{array}$ & $\begin{array}{l}5(1-5) \\
5(3-6)\end{array}$ & $\begin{array}{l}4(1-6) \\
4(1-6)\end{array}$ \\
\hline
\end{tabular}

\section{Degree of consensus}

In order to dertve a measure of the degree of 'agreement' on the likelihood of a neuroleptic response, ratings were dichotomised into 'broadly unfavourable opinion' (1-3) and 'broadly favourable opinion' (4-6) (Table 2). For each professional group (data from the psychiatrists and geriatricians were united so that numbers were comparable to that in the nursing group) and each behavioural problem. these categories were analysed statistically. using a test on proportions: if the proportion of respondents registering a 'broadly unfavourable opinion' was significantly $(P<0.05)$ greater than $50 \%$, a 'negattve view' was deemed to hold. conversely for a 'posittve view' and if there was no significant deviation from $50 \%$, an 'equitvocal view' was deemed to hold. Interestingly, no 'positive views' towards the use of neuroleptics existed among the nursing respondents for any of the behaviour problems in the questionnaire but a 'negative view' was taken towards their use for non-violent resistiveness and non-violent sexual inappropriateness, within both the nursing and medical groups. The medical group demonstrated a 'posittve view' in favour of neuroleptics for the treatment of hallucinations and paranoid thinking.

\section{Faith in neuroleptics}

Total scores were not significantly different between the psychiatrists and geriatricians (medlans 33 and 31 respectively, $z=1.35, P>0.1$ ) but medical respondents were more likely to register higher 'faith in neuroleptic' scores than their nursing counterparts (medians 32 and 29 respectively, $z=2.89, P<0.01)$. There was a greater variation of total scores among the nurses compared to the doctors (mean absolute deviations from the median total score of 5.9 and 3.9 respectively).

Table 2. Numbers of respondents with an 'unfavourable view' of neuroleptics for each indication

\begin{tabular}{lll}
\hline Bohaviour & $\begin{array}{l}\text { Doctors } \\
\mathbf{n - 3 0}\end{array}$ & $\begin{array}{l}\text { Nurese } \\
\mathbf{n m 3 1}\end{array}$ \\
\hline Predictable aggression & 12 & 15 \\
Unpredictable aggression & 11 & 15 \\
Purposeless overactlvity & 10 & 18 \\
Wandering & 18 & 19 \\
Non-violent resistlveness & 23 & 23 \\
Shouting & 14 & 19 \\
Non-violent sexual & 22 & 27 \\
$\quad$ inappropriateness & 7 & 14 \\
Paranoid thinking & 3 & 11 \\
Hallucinations & 3 & \\
\hline
\end{tabular}




\section{Comment}

Only one previous study has used a similar approach to examine the opinions of health care professionals working with the elderly. Among a group of senior American geriatricians, attempts to dertve a consensus on the use of neuroleptics for non-psychotic behaviour disturbance in dementia falled (Beers et al, 1991).

The results demonstrate a variety of opinions on the likelihood of a neuroleptic response for the behaviour problems described, both within and between professional groups. The varlation in ratings within the nursing group was particularly large. However, on a broad measure of agreement, a 'negative view' prevailed among both doctors and nurses towards the helpfulness of neuroleptics in some challenging, but non-violent behaviours. It may be that the risk of side-effects in these circumstances is thought likely to outweigh any benefits to the patient, fellow patients or carers.

By analogy with the functional psychoses, the psychotic symptoms of dementia have been characterised, in the medical literature, as being responsive to major tranquillisers although there is little evidence from placebo-controlled trials to confirm this impression (Mulsant \& Gershon, 1993). The medical staff had a more sanguine view of the role of neuroleptics than the nursing respondents, even for paranoid symptoms that could be interpreted as driven primarily by memory impairment. As measured by comparison of total scores, the nursing group indicated less 'faith' in neuroleptic therapy for dementia than their medical counterparts. The lower response rate and larger variation in scores among the nurses must be considered when interpreting this result, which is counter-intuitive to the experience of many doctors working with the elderly, who often gain the impression that nurses demonstrate excessive 'faith' in the usefulness of major tranquillisers for disturbed patients with dementia.

Comments by nursing staff highlighted the importance of a psychosocial approach towards managing the behavioural features of dementia, for example, stating that such problems are "usually secondary to the environment" and are generally responstve to "kindness and time".

Hope (1994) has argued for drug trials on the non-cognitive features of dementia using valid and reliable measures of behavioural disturbance. He suggests that psychotic symptoms and purposeless overactivity are less environmentally determined and perhaps more responsive to pharmacological interventions. However, perhaps the most important requirement in everyday clinical practice is for a sceptical, scientific approach towards the management of individual patients, incorporating rigorous baseline measures of disturbance and regular review of response and side-effects. This area is suitable for multidisciplinary audit, both within specialist and general practice settings.

\section{Acknowledgements}

I would like to thank all those who cooperated in the survey and Professor T. Arle for his helpful comments.

\section{References}

AVORN, J. \& GURWrrz, J. H. (1995) Drug use in the nursing home. Annals of Internal Medictne, 123, 195-204.

BEERS, M. H., OUSLANDER, J. G., ROLLNGHER, I., et al (1991) Explicit criteria for determining inapproprlate medication use in nursing home residents. Anchives of Internal Medictne, 151, 1825-1832.

GARRARD, J., MAKRIS, L., DUNHAM. T., et al (1991) Evaluation of neuroleptic drug use by nursing home elderty under proposed Medicare and Medicald regulations. Joumal of the American Medical Association, 268, 463-467.

HOPE, T. (1994) Behavioural disturbance in dementia. In Princtples and Practice of Gerlatric Psychiatry (eds J. R. M. Copeland, M. T. Abou-Saleh \& D. G. Blazer). Chichester: John Wiley.

MuLSANT, B. H. \& GershoN, S. (1993) Neuroleptics in the treatment of peychosis in late life: a rational approach. International Joumal of Gerlatric Psychiatry, 8, 979-992.

Nygnard, H. A., BRUdVik, E., PEDERSEn, E., et al (1994) Consumption of psychotroplc drugs in nursing home residents: a prospective study in patients permanently admitted to a nursing home. Intemational Joumal of Gerlatric Psychiatry. 9. 387-391.

SCHNEIDER, L. S., POLLCK, V. E. \& LYNESS, S. A. (1990) A meta-analysis of controlled trials of neuroleptic treatment in dementia. Joumal of the American Geriatric Society, $\mathbf{8 8}, 553-563$.

Simon Thacker, Senior Registrar in Old Age Psychiatry, Department of Health Care of the Elderly, Medical School University Hospital, Nottingham NG7 2UH 